\title{
FUNÇÕES DOS ESPAÇOS PÚBLICOS NA CIDADE CONTEMPORÂNEA ${ }^{1}$
}

\author{
Alice Viana ${ }^{2}$
}

DOI: $10.5752 / P .2316-1752.2018 v 25 n 37 p 84$

\begin{abstract}
Resumo
Este artigo tem como objetivo apresentar, de forma sistematizada e sob a ótica do planejamento, as principais funções hoje atribuídas aos espaços públicos, tais como abrigar a circulação e o estacionamento de veículos, servir de local de manifestação das práticas de lazer passivo e ativo, e de local de realização de eventos. Busca-se discutir as características necessárias para que os espaços públicos possam sediar essas atividades e também evidenciar os principais conflitos que podem surgir da coexistência dessas funções ou da absorção de funções não previamente previstas.
\end{abstract}

\footnotetext{
1. Este artigo toma por base investigação realizada durante o doutoramento de Alice Viana, cursado no Programa de Pós-graduação em Arquitetura e Urbanismo (NPGAU) da Universidade Federal de Minas Gerais (UFMG), sob orientação de Maria Lúcia Malard. 2. Arquiteta Urbanista pela UFMG, Mestre em Planejamento Urbano pela Université de Paris I - Panthéon-Sorbonne-FR, Doutora pelo Programa de Pós-graduação em Arquitetura e Urbanismo (NPGAU) da UFMG. Professora Adjunta I do Departamento de Arquitetura e Urbanismo da Escola de Minas da Universidade Federal de Ouro Preto. E-mail: aliceviana00@gmail.com
} 
Palavras-chave: Espaços Públicos. Lazer. Mobilidade. Sociabilização. Eventos. 


\section{FUNCTIONS OF PUBLIC SPACES IN CONTEM- PORARY CITY}

\begin{abstract}
This article aims to present, in a systematized way and from a planning perspective, the main functions nowadays attributed to public spaces: to harbour the circulation and the parking of vehicles, to serve as a place for the manifestation of passive and active leisure practices, as well as a place for events. It seeks to discuss the necessary characteristics for these spaces to host these activities and also to highlight the main conflicts that may arise from the coexistence of these functions, or from the absorption of functions not previously foreseen.
\end{abstract}

Keywords: Public spaces. Recreation. Mobility. Socialization. Events.
FUNCIONES DE LOS ESPACIOS PÚBLICOS EN LA CIUDAD CONTEMPORÁNEA

\section{Resumen}

Este artículo tiene como objetivo presentar de forma sistematizada, bajo la óptica de la planificación, las principales funciones hoy atribuidas a los espacios públicos: abrigar la circulación y el estacionamiento de vehículos, servir de local de manifestación de las prácticas de ocio pasivo y activo, y de lugar de realización de eventos. Se busca discutir las características necesarias para que los espacios públicos puedan albergar esas actividades y también evidenciar los principales conflictos que pueden surgir de la coexistencia de esas funciones, o de la absorción de funciones no previamente previstas.

Palabras-claves: Espacios Públicos. Ocio. Movilidad. Socialización. Eventos. 


\section{Introdução}

Por meio da observação das mudanças sociais ocorridas a partir do século XVIII e das transformações espaciais delas decorrentes, pode-se deduzir que, com o passar dos anos, novos tipos de funções foram atribuídas aos espaços públi$\cos ^{3}$. Assim, testemunha-se espaços tradicionais de circulação e trocas, como os antigos largos, serem convertidos em espaços de estacionamento, bem como jardins dedicados à contemplação serem transformados em espaços esportivos, entre outros exemplos. Com a ampliação das

3. Neste artigo, chama-se de espaços públicos os espaços livres (não edificados) de uso público, voltados, entre outras atividades, ao descanso e ao lazer da população. São exemplos: as praças, largos e parques. Compreende-se, no entanto, como ressaltam Montal e Noisette (2005), que o espaço público é também formado por uma propriedade e não apenas por uma afetação de uso. Alguns autores, como Aelbrecht (2016), consideram como público todo o espaço que é acessível ao público de forma geral, onde se manifesta a esfera pública, mesmo que esses sejam espaços privados ou espaços intermediários (semipúblicos), como os bares, shopping centers e clubes. Esses espaços são tão relevantes na cultura contemporânea que são chamados por Oldenburg (1999) de third places, terceiros lugares na hierarquia quotidiana, situando-se logo após o local de residência e o de trabalho. Percebe-se que essa visão, que considera como público todo local de apropriação pública, é bastante aceita em algumas culturas, em especial no hemisfério norte e junto aos países centrais. Em outras realidades, entretanto, a questão da natureza da propriedade é imperante e decisiva, especialmente nas quais há bastante desigualdade social. Assim, considera-se como públicos apenas aqueles espaços que sejam de propriedade púbica e cuja responsabilidade de manutenção recaia sobre o poder público, seja ele municipal, estadual ou federal. Acredita-se que esses espaços, por serem mais dissociados das atividades de consumo, sejam menos excludentes dos grupos menos favorecidos, sendo efetivamente mais públicos do que os demais espaços coletivos. 
demandas em relação a esses espaços, observa-se que sua relevância para as cidades tornou-se diretamente proporcional às diversas funções que eles podem carregar, tais como: meio de circulação e comunicação, espaço político, religioso, comercial, cívico e social (MEHTA, 2014). Nem sempre todas essas funções precisam ser observadas em um mesmo local para que ele seja bastante apropriado, mas o acúmulo de funções geralmente revela um alto grau de importância do espaço público para a sociedade local. Um exemplo é a tradicional praça central, presente nas cidades pequenas brasileiras, que costuma servir de espaço de sociabilização, passeio, recreação, consumo, manifestação política e também local de eventos festivos, sendo uma importante, senão a maior, referência municipal.

Normalmente, no momento do estabelecimento de um espaço público, seja ele uma rua, largo ou praça, ele costuma apresentar uma função (ou funções) inicialmente condizente com a sua natureza ${ }^{4}$, recebendo características arquitetô-

4. Nesta pesquisa, optamos pelos termos "natureza" ou, ocasionalmente, "vocação," para designar as potencialidades de um espaço livre de uso público conferidas a ele por suas características arquitetônicas e urbanísticas, e o termo "função" para o tipo de utilização que esse espaço apresenta na prática. Por exemplo, a existência de uma quadra esportiva em uma praça Ihe confere a natureza de espaço de lazer ativo. Entretanto, se essa quadra encontra-se constantemente vazia, por não haver público para essa atividade, ou por esta não apresentar condições de uso, consideramos que a prática de lazer 
nicas que permitam a realização das atividades previstas ${ }^{5}$. Pode-se citar como exemplo os jardins públicos de contemplação e descanso, que normalmente são concebidos com vegetação ornamental e assentos, assim como barreiras para elementos do entorno que poderiam comprometer a sensação de isolamento geralmente oferecida por esse tipo de equipamento. No entanto, compreendendo a relativa impermanência dos costumes e consequente obsolescência de algumas práticas, percebe-se que, com o passar do tempo, espaços públicos como esses podem tanto perder funções antigas quanto receber novas funções. Dessa forma, um jardim de contemplação pode deixar de ser um local de desfile das classes mais abastadas e passar a ser utilizado como local de prática de caminhada esportiva, ou de recreação, alterando sua função principal e, eventualmente, seu público.

Pode-se, assim, deduzir que novas formas de utilização, de-

\footnotetext{
ativo não seja a sua função, mas apenas um potencial não-explorado. Ao mesmo tempo, um largo de uma cidade histórica cujas paisagens naturais e sociais sejam preciosas não pode ser considerado como uma área que tenha "natureza" de espaço de estacionamento, mas ele pode exercer essa função enquanto assim lhe for permitido.

5. Estamos nos referindo, claramente, a espaços planejados, desenvolvidos intencionalmente para a realização de atividades previstas. Não estamos excluindo a possibilidade de espaços não-planejados serem utilizados, quotidianamente ou ocasionalmente, como espaços de lazer e encontro pela população, nem a possibilidade da população subverter a utilização prevista para um determinado espaço planejado com apropriações de outras naturezas.
} 
correntes de transformações temporais ou resultantes de transgressões dos usos esperados, podem prescindir, ou não, de adaptações físicas desses espaços que ratifiquem suas novas funções. Algumas funções não previstas inicialmente independem de quaisquer adaptações espaciais para que sejam exercidas; outras podem ser facilmente conferidas a espaços públicos pré-existentes dependendo somente da montagem de estruturas efêmeras. Pode-se mencionar como exemplo a utilização de espaços públicos como locais de exibição de filmes, prescindindo apenas de espaço livre o suficiente para a colocação de telas infláveis e área disponível para a congregação de espectadores, como ocorre anualmente no festival de cinema CINE-OP, em Ouro Preto-MG. Outro exemplo é a montagem de estruturas temporárias de vôlei de praia ou de patinação no gelo, como já é tradicional em algumas cidades europeias, para a comemoração da chegada das estações de verão e inverno, respectivamente. Ocasionalmente, alguns espaços podem adquirir novas funções apenas com a interdição de alguns tipos de atividades predominantes, mesmo que temporariamente, como a interrupção do trânsito de veículos no Elevado João Goulart ${ }^{6}$, na cidade de São Paulo, aos finais de semana. Sem circulação veicular, o espaço é utilizado livremente como área de lazer e prática de espor- 
tes, não necessitando da instalação de nenhum mobiliário especial para que essas atividades ocorram ${ }^{7}$.

Dependendo do tipo de funções a serem absorvidas posteriormente, no entanto, os espaços públicos podem prescindir de adaptações físicas mais expressivas, que podem complementar suas funções originais, ou substituílas. Toma-secomo exemplo o caso da Quinta da Boa Vista ${ }^{8}$, parque municipal carioca que, nos anos 1940, foi adaptado para receber o Jardim Zoológico do Rio de Janeiro; ou mesmo a recente inclusão, em espaços públicos brasileiros, de equipamentos pré-fabricados destinados à prática de musculação. Observa-se, assim, que a adaptação a novas demandas pode ser bem sucedida e causar poucos im-

7. Existem igualmente diversos tipos de usos não previstos que podem ocorrer de maneira mais ou menos espontânea, sem qualquer envolvimento do poder público para a sua realização. Um exemplo é o evento Praia da Estação, que ocorre em Belo Horizonte, no qual grupos de usuários ocupam a Praça Rui Barbosa com atividades de lazer e sociabilização que se assemelham àquelas observadas em praias, com a livre colocação de cadeiras de praia e guarda-sóis, aproveitando de maneira alternativa o espaço seco da ampla praça no centro da cidade. Esse e outros tipos de usos (ou contra-usos), no entanto, não são o foco deste trabalho, por geralmente não prescindirem de alterações espaciais prévias, ficando a cargo dos próprios usuários a adaptação desses locais segundo suas demandas. Reconhecemos a relevância desses usos, mas acreditamos que as possíveis transgressões manifestas por eles são parte de uma discussão política mais ampla, que já vem sendo competentemente abordada em outros trabalhos, como Leite (2004), Harvey (2014) e Delgado (2011).

8. Antiga fazenda nos tempos coloniais, que foi convertida em residência da família real portuguesa, depois utilizada como residência da família imperial brasileira e depois transformada em parque aberto à população. 
pactos nos espaços públicos, ou ao menos causar poucos impactos negativos, fazendo com que tais espaços respondam a demandas mais contemporâneas e escapem do risco de cair em obsolescência. Entretanto, em alguns casos, a adoção de algumas funções pode comprometer práticas pré-existentes consideradas positivas para a sociedade, colaborando até mesmo para a degradação desses espaços públicos e para seu esvaziamento.

Dessa forma, compreende-se que as funções exercidas pelos espaços públicos podem estar de acordo com suas potencialidades ou podem estar em desacordo, revelando-se como verdadeiros problemas. Apresentar-se-ão, assim, algumas funções atualmente atribuídas aos espaços livres de uso público, discorrendo sobre suas relevâncias para a cidade e para a sociedade contemporâneas, e sobre alguns conflitos comuns decorrentes da sua ressignificação. Serão discutidos também os elementos capazes de atribuir funções a um espaço, comparando visões de alguns especialistas.

\section{Circulação e estacionamento}

Geralmente, as vias e os largos são os primeiros espaços públicos de toda e qualquer ocupação, servindo à circulação em seu território. Logicamente, para que esses e outros espaços públicos sejam espaços de circulação, é ne- 
cessário que sirvam de elementos de ligação entre pontos distintos do assentamento, podendo permitir a passagem simultânea de pedestres, de animais e de veículos, ou restringindo o acesso a qualquer um destes. Essa circulação pode ocorrer: 1) por todo o espaço de forma indistinta, como nas ruas, nos largos e nas praças secas; 2) direcionada em múltiplos caminhos através dos recintos dos espaços públicos, como nos parques e em algumas praças ajardinadas; ou 3) de forma marginal a ele, como é comum nas praças e jardins que tomam a forma de ilhas viárias, cujo centro é inteiramente destinado à vegetação.

Percebe-se que a circulação de pedestres tende a ser proporcional à vitalidade dos espaços públicos, sendo a circulação amplamente aceita como ponto de partida para as demais formas de apropriação. Entretanto, a circulação de veículos não é garantia de sucesso (ou de insucesso) de um espaço público; pode-se apenas ponderar que, quanto maior for a circulação de veículos, maior deverá ser a atenção dada aos possíveis conflitos decorrentes da coexistência dela com os demais tipos de circulação e com outras formas de apropriação. Assim, percebe-se que espaços públicos de tipologias mais antigas e indissociáveis do sistema viário, como os largos e praças secas presentes nos centros históricos, naturalmente estarão mais sujeitos à circulação veicular, se assim lhes for permitido e, consequentemente, mais sujeitos aos impactos negativos que 
podem ser gerados por ela.

Geralmente espaços que apresentam conflitos entre circulação veicular e de pedestres demandam moderadores de tráfego, como sinalização específica, balisadores, pisos trepidantes e outros redutores de velocidade. Assim, verifica-se em várias experiências mundiais ${ }^{9}$ que para se garantir a segurança da circulação de pedestres, muita vezes não é necessário desarticulá-la completamente da circulação veicular como um todo, como defendia o urbanismo modernista. Faz-se útil, no entanto, reduzir o espaço dedicado aos veículos e impor uma velocidade máxima a eles, fazendo com que os demais tipos de circulação tenham prioridade no espaço compartilhado. Entretanto, em espaços mais centrais, cuja aglomeração de pessoas e fluxos talvez seja muito grande, é essencial que se invista paralelamente em modais de transporte público de diferentes capacidades,

9. Como as experiências européias do grupo "30km/h $(20 \mathrm{mph})$," que defende a velocidade máxima de $30 \mathrm{~km} / \mathrm{h}$ em várias zonas urbanas, argumentando que esse limite resulta em um número consideravelmente menor de acidentes, menor emissão de gases, menor produção de ruídos, menores congestionamentos e uma maior compatibilidade com outras formas de transporte, como a mobilidade pedestre, o uso de bicicletas e o transporte público de forma geral. Dentro do grupo de pedestres, destacam-se os benefícios para as crianças, os idosos e todos os demais perfis de pessoas com mobilidade reduzida. Disponível em: <http://en.30kmh.eu>. Acesso em: 17 out. 2017. 
coibindo a utilização dos carros e reduzindo a necessidade de seu emprego. É importante também que se planejem locais destinados ao estacionamento dos veículos, pois os espaços públicos podem ser muito impactados por eles.

Para que um espaço público seja utilizado como local de estacionamento, é necessário, antes de tudo, que ele disponha de área sobressalente à circulação. Observa-se que nas centralidades principais, onde normalmente se encontra grande parte dos espaços públicos das cidades, basta a existência de espaço sobressalente para que ele se encontre constantemente ocupado por veículos estacionados. Verifica-se pela experiência que, quanto maior a área sobressalente, mais ela será lembrada pela população como referência de local de estacionamento, e maior será o número de concorrentes às suas vagas. Assim como na questão da circulação, os espaços públicos de origens mais antigas, como os largos e as praças secas, são particularmente ameaçados por esse uso, justamente por apresentarem menos mobiliário e disporem de mais área desobstruída.

Pode-se afirmar que a disponibilidade de estacionamento é atualmente um dos maiores problemas nos centros urbanos, pois, devido à ampla adoção dos automóveis como meio de transporte, tal disponibilidade nunca parece ser suficiente. Ao mesmo tempo, observa-se que os estacionamentos também podem provocar vários problemas quando 
existentes em grande número (poluição visual, ocupação desmesurada do espaço público, conflitos com outras formas de apropriação, etc.) Por outro lado, a construção de prédios de estacionamentos ou de estacionamentos subterrâneos são iniciativas interessantes, mas são dispendiosas e, muitas vezes, provocam também impactos consideráveis no entorno.

O que aprende-se nas últimas décadas é que esse é um problema que aparentemente não será solucionado enquanto a circulação de carros particulares não for mesmo deliberadamente inibida, principalmente nas culturas nas quais há muita desigualdade de renda. Nestas, a costumeira precariedade de transportes públicos fará com que a posse de um carro seja almejada por grande parte da população, sendo um instrumento de diferenciação social e, também, essencialmente, um facilitador da vida quotidiana. Assim, observa-se que, sem um empenho na redução dos carros, haverá uma tendência forte para que os espaços públicos, acima de quaisquer outras funções, sejam majoritariamente espaços de circulação e estacionamento, a não ser que exista uma política urbana firmemente preocupada em equilibrar esse uso com as práticas de lazer.

\section{Práticas de lazer passivo}

Além da circulação, as funções ligadas ao lazer passivo (ou 
contemplativo) são consideradas algumas das mais comumente associadas aos espaços públicos, podendo se dividir em funções de contemplação (de vistas naturais ou culturais/edificadas), de sociabilização (ativa ou passiva ${ }^{10}$ ) e de entretenimento pessoal (leitura, prática de instrumentos musicais, uso de smartphones, reflexão e meditação, entre outros $^{11}$ ). Geralmente essas funções não se encontram de forma dissociada, pois os atributos para que ocorram costumam ser os mesmos. Essas atividades geralmente são as mais numerosas em qualquer espaço público porque são mais ligadas às práticas quotidianas e se caracterizam pela sua natureza mais inerte. Podem ser breves e ocorrer entre as atividades do dia a dia, mas, para que sejam mais frequentes e duradouras, elas demandam não apenas qualidades urbanísticas em seu entorno, mas também o investimento na qualidade espacial do espaço público em si.

As atividades de lazer passivo são muito associadas aos espaços públicos produzidos a partir do final do século XVIII,

10. Atividade por vezes chamada na cultura anglo-saxônica de "people-watching" - o ato de se observar as pessoas em ambientes públicos ou semipúblicos sem dar a nenhuma delas atenção especial. Nessa prática, o indivíduo sente-se parte da vida urbana sem necessariamente realizar nenhum contato ativo (conversação ou toque), recebendo informações apenas por meio da visão e da audição (GEHL, 2010).

11. O descanso do corpo não é considerado inicialmente uma atividade de lazer, mas o incluímos nesse grupo por considerarmos que a partir de um momento de descanso, geralmente desenvolvemos pelo menos uma das atividades de lazer passivo - contemplação, sociabilização (mesmo que apenas passiva) e entretenimento pessoal. 
como os já mencionados jardins urbanos, cuja composição bucólica e solo muito ocupado por vegetação refletia a cultura de lazer da época - a contemplação da paisagem, o desfile, a pequena sociabilização. Entretanto, essas atividades não se limitam a esse modelo de espaço público, pois a sua independência de estruturas específicas permite que elas sejam desempenhadas em quase qualquer lugar. Toma-se como exemplo a contemplação - as ruas, praças e largos das nossas cidades que costumam oferecer acesso a monumentos históricos ou locais importantes para a memória coletiva, que também são objetos de observação e de admiração. Magnoli (2006) nos lembra que, nos espaços livres públicos, ratifica-se a importância simbólica dos poderes urbanos tradicionais, manifestos nas edificações monumentais do Estado e da Igreja. Suas formas, materiais e ornamentos, também são testemunhos da cultura historico-urbanística da cidade.

Outra atividade bastante tradicional e rotineira no espaço público é o consumo, em especial, de gêneros alimentícios. Nessa caso, refere-se tanto aos produtos alimentícios de abastecimento primário, como os hortifrutigranjeiros comercializados em feiras e por vendedores ambulantes, quanto aos produtos de consumo imediato (alimentos preparados), como sanduíches, sucos, entre outros. Observa-se que as praças e largos das cidades antigas sempre foram espaços de trocas, pois sediavam feiras bem antes 
da existência de lojas e outros equipamentos comerciais, responsáveis por grande parte da animação urbana. Assim, a disponibilidade de comércios e, em especial, de comércios e serviços alimentícios, ainda é considerada como um grande influenciador da permanência nos espaços públicos, atraindo e retendo usuários. Além dos produtos alimentícios, a venda de vários outros produtos, tanto nas edificações do entorno quanto na forma de ambulantes, podem dinamizar os espaços públicos, atraindo pessoas e criando elementos de triangulação. Quando os espaços públicos são ocupados pela exposição de produtos ou de stands de venda, o movimento de pessoas atraídas por eles geralmente é responsável pela atração de outras pessoas, e a disposição de mesas e cadeiras em seus recintos para dar suporte a esse consumo pode incentivar a permanência e a sociabilização ${ }^{12}$.

Na clássica obra de William $\mathrm{H}$. Whyte, The social life of small urban places (1980), o autor nos apresenta o resultado de um trabalho de anos de observação do movimento quotidiano de praças urbanas na cidade de Nova York (EUA), nas

12. Compreendemos, entretanto, que essa questão é controversa, pois, por vezes, a exposição de produtos gera prejuízo para a circulação. Defendemos também que a exploração de parte do espaço público por empresas privadas deve ser feito por meio de licitação; deve ser de comprovado benefício público e não deve exigir qualquer obrigação de consumo mínimo por parte da população. 
quais a maior parte das atividades era do tipo de lazer passivo e de consumo. Nessa pesquisa, ele identifica como elementos-chave para a apropriação dos espaços públicos a existência de áreas assentáveis (não necessariamente bancos, mas também degraus, canteiros e muretas), de elementos de qualificação ambiental (áreas ensolaradas e sombreadas, circulação de ar, a presença de árvores e também de elementos aquáticos tangíveis), de oportunidades de alimentação (fixa ou ambulante), de proximidade de vias com fluxos razoáveis de pedestre e de elementos de triangulação (elementos como artistas de rua, monumentos, alguma coisa ou assunto em comum que possa fazer com que um contato inicial entre estranhos aconteça).

As áreas assentáveis são consideradas o ponto de partida para a fixação dos usuários - logicamente fazem com que exista a possibilidade do descanso do corpo, da permanência (em contraposição à simples passagem), permitindo que ali se desenvolvam atividades mais duradouras de contemplação, de sociabilização e de entretenimento pessoal. Assim, são imprescindíveis para os espaços públicos que se destinam à função de lazer passivo, e a mera existência desse tipo de elemento confere aos espaços públicos o potencial para que se exerçam essas atividades. Os demais elementos identificados por Whyte vão qualificar a experiência dessa permanência no espaço, vão potencializar as apropriações, fazendo com que essas sejam mais agradá- 
veis e, por consequência, mais numerosas, mais frequentes e mais duradouras.

Entretanto, para que existam apropriações é necessário, primeiramente, garantir que existam pessoas frequentando o espaço circundante - ou seja, fluxos constantes nas vias que the dão acesso. Assim, observa-se que os espaços livres de uso público tendem a ser mais utilizados para o lazer passivo quando seu entorno tem geradores de fluxo, como comércios, serviços e instituições. Harrison (2006) argumenta ainda que, se a diversidade de usos funciona como um atrativo para a população, um espaço público atrativo pode também incentivar o estabelecimento de comércios e serviços no entorno, assim como a presença de ambulantes, formas importantes de geração de emprego e renda para os cidadãos. Em contextos turísticos, então, observa-se que o fortalecimento do setor terciário, em especial dos estabelecimentos de hotelaria e alimentação ${ }^{13}$, é fundamental para a economia local, sendo seu sucesso diretamente proporcional à qualidade dos espaços públicos aos quais se encontra conectado.

13. Na França, utiliza-se o termo HORECA (Hôtels, Restaurants et Cafés) para esse conjunto de atividades econômicas extremamente ligadas à atividade turística e às centralidades em geral, e são numerosas nesse país as pesquisas sobre o tema. 
Gordon Cullen (2010), em sua obra Paisagem urbana ${ }^{14}$, também diz que "(...) abrigo, sombra, conveniência e um ambiente aprazível são as causas mais frequentes da apropriação de espaço, as condições que levam à ocupação de determinados locais" (p. 25). Em seu estudo, mostra que a instalação de elementos de caráter permanente podem transformar espaços urbanos considerados apenas de passagem (fluidos, porém monótonos) em espaços de constantes "ocupações periódicas", ou seja, de apropriações de curta a média duração. Ou seja, como Whyte, Cullen identifica que um local que já possua certa vitalidade graças à circulação de pessoas, pode se tornar também um local com potencial para outras atividades caso receba mobiliário que ofereça oportunidades de apropriação. Entretanto, apesar do autor não se ater a essa questão, percebe-se que a disposição desses elementos no espaço público não garante, necessariamente, essas apropriações. Assim, acredita-se que sua distribuição no espaço não deva ser algo aleatório, mas que sua implantação prescinda de uma observação atenta das características espaciais e funcionais do recinto. Outra questão a ser pensada é que esses elementos não necessitam ser fixos, de natureza mais imutável; ou seja, pode-se ambientar um espaço com mobiliário móvel, garantindo sua flexibilidade, mas de forma que eles estejam

14. Publicado originalmente em 1961. 
quotidianamente presentes no espaço (diferente de instalações inteiramente efêmeras).

A questão da qualidade na disposição de elementos é abordada em Criando Paisagens, do paisagista Benedito Abbud (2006), que defende que, no ato projetual, os espaços livres devam ser pensados como "cômodos externos". Estes, assim como os internos, apresentam planos de piso (revestimentos inertes, gramados, espelhos d'água), planos verticais (fachadas das edificações, muros, cercas, taludes, montanhas e maciços vegetais verticais) e planos de teto (copas das árvores, pergolados, marquises), e devem ter um layout que facilite as apropriações. O mesmo argumento é levantado por Childs (2006), que o completa dizendo que, assim como as salas de estar, bons espaços públicos têm bordas repletas de áreas assentáveis, centros abertos e desobstruídos, facilitando a circulação, a visibilidade e as livres-apropriações. O autor, assim como Whyte (1980), levanta ainda o importante papel das esculturas e outras obras de arte no espaço público pois, além de serem elementos de contemplação e de discussão, podem servir de marcos, de pontos de encontro, de estruturas identitárias do lugar ${ }^{15}$.

15. Lembramos aqui do incrível magnetismo da escultura Cloud gate (2006), do artista indo-britânico Anish Kapoor no Millennium Park, em Chicago (EUA). A possibilidade de 
Jan Gehl, em sua influente obra Cities for people (2010), retoma muitas das discussões iniciadas em Life between buildings $^{16}$ (2011), dentre as quais a necessidade de uma boa qualidade espacial para que as pessoas busquem os espaços públicos para o desenvolvimento de atividades além das obrigatórias, criando com eles um número maior de vínculos. Para se atingir a qualidade espacial desejada, o autor defende que é preciso se compreender certos aspectos da natureza humana, como o funcionamento dos sentidos, a escala corpórea e as dimensões mínimas e máximas para que os contatos ocorram. O autor faz um estudo sobre a relação entre os espaços públicos e os privados, se detendo sobre como os indivíduos tendem a se reter nos espaços intermediários entre esses (nas bordas), principalmente para as atividades de contemplação e sociabilização. Assim, ressalta a importância de fachadas ativas ${ }^{17} \mathrm{e}$

\footnotetext{
tocar na escultura, de se passar por baixo desta e de ver a si mesmo e a paisagem urbana refletida em sua superfície curva provoca um vínculo imediato e irresistível dos usuários do local com a obra de arte. Nos anos 1970 e 1980 testemunhávamos uma reação similar, ainda que não tão forte, nos visitantes do edifício do Congresso Nacional, em Brasília/ DF, projeto de Oscar Niemeyer, com o terraço que dá acesso às cúpulas dos plenários do Senado Federal e da Câmara Federal. A cúpula do plenário do Senado (voltada para baixo) era constantemente apropriada pelos visitantes, que competiam por quem conseguisse alcançar o topo primeiro. O terraço todo, antigamente utilizado como praça seca por turistas e pela população local, em especial nos finais de semana, hoje se encontra interditado à visitação comum.

16. Inicialmente publicada em 1971.

17. Fachadas que tenham permeabilidade total, possibilitando o contato do interior da
} 
também da existência de geradores de fluxos nos entornos das praças urbanas.

Em relação às características arquitetônicas, Gehl (2010) defende a implantação de várias estruturas de sustentação do corpo, tanto do tipo assentável quanto também dos tipos que servem de apoio à postura em pé, atraindo apropriações intermediárias entre a breve passagem e a permanência de maior duração. Essas estruturas são consideradas úteis principalmente para momentos de sociabilização ativa entre estranhos, ou de sociabilização passiva durante a espera entre compromissos do dia. Diferentemente de Whyte (1980), Gehl não chega a oferecer medidas e quantidades ideais para os elementos qualificadores, mas oferece uma "caixa de ferramentas" contendo doze critérios de qualidade espacial divididos em três grupos: proteção (contra tráfego e acidentes; contra o crime e a violência; contra condições climáticas adversas), conforto (oportunidades para caminhar, permanecer em pé, sentar, ver, ouvir, brincar e praticar atividades físicas) e prazer (observância da escala humana, oferta das boas sensações térmicas e promoção de outras experiências sensoriais positivas).

edificação com o exterior dela (com o espaço público, geralmente) ou, ao menos, permeabilidade visual, garantida por vitrines e janelas. 
Em relação às atividades de sociabilização, autores de outras áreas do conhecimento também ressaltam que as características arquitetônicas dos espaços públicos podem ser bastante definidoras dos tipos de interação que neles ocorrem. A socióloga Lyn Lofland, em The public realm (2009), ao investigar as interações entre desconhecidos, destaca o papel universal de espectador dos usuários do espaço público, papel esse que pode ser ocasionalmente revertido em papel de ator - aquele que é o observado ${ }^{18}$. A autora discorre sobre como a atratividade do espaço público se deve, em grande parte, não apenas às vistas naturais e culturais de destaque, mas também a esse jogo de ver e ser visto - da constante troca entre os papéis de ator e espectador. Platôs, pisos elevados, muretas assentáveis e escadarias, são elementos que geralmente colocam seus usuários em posição de destaque, sendo apropriados por indivíduos ou grupos que, se não estão à busca de exposi-

18. São cinco os princípios de interação entre desconhecidos (principles of stranger interaction) identificados por Lofland em sua obra The public realm (2009): (1) Cooperative Motility: movimentos quase coreografados entre pedestres e veículos de forma que eles nunca colidam; (2) Civil Innatention: forma de se reconhecer o direito à presença do outro e ao mesmo tempo ignorá-lo para que este se sinta à vontade no espaço coletivo; (3) Audience Role Prominence: atividade na qual o usuário do espaço é, primordialmente, audiência para a vida urbana, para as ações do outro; (4) Restrained Helpfulness: pequenas gentilezas que são feitas a estranhos sem a criação de maiores vínculos, como informar as horas ou uma direção e (5) Civility toward Diversity: o tratamento cordial universal, independentemente de sua cor, sexo, religiosidade, ou aparência de forma geral. 
ção, ao menos não se sentem constrangidos ao serem observados pelos demais. O centro desobstruído de espaços mais amplos também pode ser considerado uma área de destaque quando existem oportunidades de assento nas bordas.

Assim como defende Childs (2010),e também Sitte (1996), em sua clássica obra L'art de bâtir les villes: I'urbanisme seIon ses fondements artistiques ${ }^{19}$, acredita-se que a manutenção de espaços centrais desobstruídos em ambientes livres públicos seja fundamental. Não se quer dizer com isso que um espaço público não precise de mobiliário, ou que possa ser apenas um mero vazio. Acredita-se, no entanto, que áreas desobstruídas, em alguns casos, facilitam não apenas a contemplação do conjunto edificado e o jogo de observação, como descrito por Lofland, mas também uma maior flexibilidade de ocupação, de transmutação do espaço. Uma maior moderação na ocupação do recinto com elementos fixos faz com que ele possa ser utilizado para a colocação de mobiliário móvel e, também, ocasionalmente apropriado para a realização de atividades de lazer ativo e de eventos. 
Dessa forma, pode-se observar que espaços livres de uso público que não disponham de elementos incentivadores de apropriações em seu recinto podem ser apenas vazios urbanos; ao mesmo tempo em que, sem um entorno dinâmico, alguns espaços podem ser agraciados com vários tipos de móveis e outros elementos e ainda sim não serem muito apropriados para atividades de lazer passivo. Ou seja, o sucesso dos espaços públicos como locais de encontro, sociabilização, contemplação e entretenimento depende de uma observação sensível de suas características e de seus potenciais, e o que funciona para um pode não funcionar para os demais. Assim, apesar de considerar-se de grande relevância o trabalho dos autores supracitados, percebe-se que os elementos por eles defendidos - especialmente a inserção em ambientes urbanos já dinâmicos e a disponibilidade de mobiliário - não são necessariamente garantia de sucesso dos espaços públicos, mas a experiência nos faz considerar que esses realmente sejam fortes atratores de apropriações.

É importante perceber que a observância a conjuntos complexos de critérios de qualidade, como a "caixa de ferramentas", estabelecida por Gehl (2010), chega a soar como algo utópico ou pertinente apenas a espaços públicos de grande alcance espacial e que tenham que suprir 
a deficiência de muitos outros em termos de programa de atividades ${ }^{20}$. No entanto, acredita-se que esses critérios possam ser aplicados, não necessariamente todos em um mesmo espaço, mas em um conjunto de espaços públicos bem interligados, que funcionem como um sistema de áreas livres complementares. Assim, podem permitir que diversas atividades ligadas ao lazer passivo, ao consumo e a outras atividades se distribuam de forma distinta nos espaços públicos das cidades, gerando uma maior adequação às diferentes intenções e perfis de usuários.

\section{Práticas de lazer ativo}

A prática de esportes e a recreação são tipos de atividades que, diferentemente daquelas incluídas no conjunto do lazer passivo, são mais dinâmicas, apresentando uma maior intensidade de movimentos. A adoção de elementos voltados ao esporte e à recreação em espaços livres de uso público ocorreu simultaneamente à criação de muitos parques no século XX que, de modo diferente dos grandes jardins públicos urbanos do século XIX, já apresentavam

20. Apesar da grande validade desses trabalhos, é importante observar que as realidades política, histórica, econômica, e até mesmo ambiental a qual os espaços públicos brasileiros estão submetidos, diferem muito das realidades europeias ou norte-americanas. 
um maior equilíbrio entre áreas secas e ajardinadas. Observa-se que esses elementos vêm sendo também implantados em praças e em outros espaços públicos mais naturalmente conectados às dinâmicas urbanas, não apenas nos ambientes mais contemporâneos, mas também nos espaços considerados históricos. Um exemplo é o caso da reforma da Praça Floriano Peixoto, em Belo Horizonte, de origem do final do século XIX e de inspiração clássica, que nas últimas décadas foi adaptada para ser local não apenas de lazer passivo, mas também de recreação e esportes

A praça moderna foi ratificada socialmente como elemento necessário à vida na cidade. (...) O lazer contemplativo e o caráter de conveniência social continuam sempre presentes; o lazer esportivo e a recreação infantil foram definitivamente incorporados; e o lazer cultural começou a se manifestar com vigor no programa moderno. Os equipamentos como quadras esportivas, playgrounds e brinquedos infantis, palcos e anfiteatros ao ar livre, passaram a ser implantados com freqüência, confirmando essas novas formas de uso da praça. (ROBBA; MACEDO, 2010, p.37-38)

Atualmente, muitos espaços públicos vêm sendo repensados para incluir em seus recintos ao menos algum tipo de atividade de lazer ativo, e proliferam equipamentos produzidos em massa, tanto para a recreação, quanto para a prática de atividades esportivas. Acredita-se que a adoção desses equipamentos nos espaços livres de uso público, no entanto, deveria ser feita de forma mais crítica, pois muitas vezes 
os modelos utilizados não são adaptados para as condições climáticas locais, oferecendo temperaturas pouco confortáveis ao toque, ou mesmo materiais pouco resistentes às chuvas e à umidade. A implantação deles pode, também, inibir outras formas de apropriação, principalmente quando feita sem um estudo das características e anseios da população usuária do espaço. Assim, podem trazer benefícios ao espaço público, ampliando o rol de opções de entretenimento, mas podem também ser verdadeiros entraves à fruição do local.

Observa-se que, mesmo com a disponibilidade de equipamentos específicos, muitos indivíduos buscam nos espaços públicos a possibilidade de realização de atividades esportivas mais livres, como a prática de caminhada e corrida, necessitando, para isso, apenas de uma superfície com um tipo de pavimentação mais regular e de uma extensão grande apenas o suficiente para que o percurso não seja tão repetitivo. Algumas atividades coletivas, como o yoga e o tai-chi-chuan, também não necessitam de suporte específico, apenas de área livre e relativamente plana, com pavimentação um pouco mais lisa, ainda que antiderrapante. A constatação desse fato nos mostra que muitas atividades esportivas poderiam ser incluídas em espaços públicos que não foram inicialmente pensados para propiciá-las, 
bastando talvez gerenciar possíveis conflitos com outras atividades ${ }^{21}$ e incentivá-las por meio de uma programação regular ${ }^{22}$.

Em relação à recreação, observa-se também que, embora existam brinquedos produzidos especificamente para a instalação em áreas externas e em espaços públicos, há uma tendência em muitos projetos contemporâneos internacionais de criação de playgrounds com elementos de design mais flexível, menos direcionados a um tipo específico de apropriação. Compreende-se que, embora os brinquedos infantis tradicionais sejam adequados, muitas vezes as crianças se apropriam muito bem de áreas mais livres e de pequenos desafios, como a escalada de topografias artifi-

\footnotetext{
21. Como a interdição à circulação veicular em parte do espaço público em dias de tráfego menos intenso, permitindo a ocupação parcial do espaço por outras práticas, ou mesmo o gerenciamento de tipos de atividades para diferentes faixas etárias. Espaços que são apropriados para a prática de esportes que utilizam bolas podem oferecer riscos à recreação de pequena infância quando manifestos simultaneamente - assim, a utilização de barreiras móveis para a separação de áreas pode colaborar para garantir a segurança na prática de diferentes demandas.

22. Alguns grupos de usuários sentem-se confortáveis para subverter o padrão de ocupação de um espaço, inserindo neles atividades não inicialmente previstas, como a prática do skate, do bicicross ou do Le Parkour. Muitas vezes, no entanto, a população local precisa de incentivo para enxergar que um espaço público possa também ser utilizado como local de lazer ativo. Assim, observa-se que algumas prefeituras têm promovido, em conjunto com outros atores, aulas coletivas de dança e artes marciais em praças e parques, servindo de ação inicial para que outras atividades possam acontecer de forma mais espontânea.
} 
ciais e de mobiliário de uso menos pré-definido. É possível também trabalhar com mobiliário móvel, como estruturas infláveis ou mesmo desmontáveis, caso o espaço precise ser desobstruído em algumas datas. Esse tipo de mobiliário de recreação é especialmente útil quando se tem espaços públicos com limitações de intervenção, que devam ser compartilhados com outros usos, ou que tenham diferentes tipos de apropriação em diferentes horas do dia. Assim, volta-se a defender a flexibilidade ao menos parcial do espaço, particularmente facilitada pela não ocupação de algumas áreas com mobiliário fixo, específico ou vegetação ${ }^{23}$.

Considera-se, igualmente, que a disponibilidade de espaço desobstruído e plano (ou de declividade suave) seja apenas um ponto de partida para que ocorram atividades recreativas e esportivas. Outros elementos de qualificação, no entanto, como estruturas de sombreamento, iluminação adequada, pisos especiais e vestiários, por exemplo, poderiam potencializar tais experiências, podendo atrair e reter um número maior de usuários e também oferecer condições

23. É, no entanto, importante lembrar que a recreação é uma atividade que muitas vezes prescinde não apenas de espaço livre e de mobiliário específico ou ao menos de equipamentos interativos e seguros, mas também de áreas assentáveis, protegidas do sol excessivo, pois as crianças geralmente frequentam os espaços públicos acompanhadas de adultos, que muitas vezes não tomam parte nas brincadeiras e permanecem às margens dessas na função de observação atenta. 
de uso em horários diferentes ${ }^{24}$.

\section{Eventos: festas sagradas ou profanas, manifes- tações cívicas e políticas}

Como bem coloca Childs (2006), quando presenciamos um sentimento coletivo de alegria ou de perda é comum buscarmos uns aos outros, e o espaço normalmente eleito para essa reunião em grande escala é o da esfera pública. Mesmo com a grande potencialidade de sociabilização nos meios digitais, percebe-se que o espaço público ainda é fortemente requerido como espaço de encontro e manifestação. É nele que podemos perceber, com todos os nossos sentidos, que fazemos parte de um grupo. Dessa maneira, compreende-se que uma praça pode ser utilizada como espaço de encontro por vários pequenos grupos de conhecidos, em um tipo de sociabilização que ainda se mantém na esfera privada (ainda que o espaço em si seja público), ou pode ser inteiramente ocupada por um grande grupo de desconhecidos ou semidesconhecidos, reunidos por uma causa em comum, conferindo sentido realmente público aquele lugar.

24. A esses elementos de atratividade somam-se, evidentemente, outros, relativos à atratividade do entorno já mencionados e também às questões de manutenção do espaço (limpeza, sensação de segurança, entre outros). 
O espaço livre de uso público pode, assim, servir de lugar tanto para as festas e manifestações artísticas e culturais mais tradicionais, como o Carnaval, as festas juninas e as procissões religiosas, ainda muito comuns nas cidades brasileiras, como também para eventos de costume mais recente, como os grandes festivais contemporâneos de cinema, de teatro e de música. Além disso, pode abrigar manifestações de caráter cívico, como a comemoração de um fato importante para a história daquela localidade, ou para as manifestações de contentamento ou descontentamento de cunho político. Childs (2006) salienta ainda que, embora espaços livres públicos geralmente sejam mais utilizados quando o clima está ameno e agradável, alguns eventos são capazes de atrair multidões, mesmo sob calor ou frio intenso. A capacidade de atrair a população mesmo quando as condições climáticas são mais intensas vai depender da forma como o espaço público é capaz de minimizar essas sensações (proteção aos ventos mais frios, disponibilidade de sombreamentos agradáveis, etc.), especialmente quando esses eventos estão ligados a sensações de prazer, como as propiciadas pelas festas culturais. Observa-se, no entanto, que alguns outros eventos, como os de caráter mais político, não parecem tão dependentes das características que oferecem conforto, sendo mais ligadas aos elementos simbólicos do espaço em si.

As funções cívica e política andam sendo muito discutidas 
nos últimos anos graças a numerosos eventos recentes de ocupações de espaços públicos por massas descontentes em diversas realidades urbanas globais. Borja e Muxì (2000) atribuem essas funções aos espaços públicos por serem os locais responsáveis por permitir a expressão coletiva, as manifestações, a visibilidade dos diferentes grupos sociais, tanto nas áreas centrais quanto nos bairros. Argumentam que o espaço público é um meio de cidadania para os marginalizados, um local que faz crescer sua autoestima, e onde eles percebem que não estão sozinhos em sua luta. A cidadania, segundo os autores, representa um desafio político, social e especificamente urbano, fazendo com que as centralidades, a mobilidade e a acessibilidade, a qualidade e visibilidade dos bairros e, principalmente, a força de integração dos espaços públicos, contribuam para dar sentido à vida cotidiana.

Harvey (2014) chama a atenção para a importância dos espaços públicos como espaços políticos, pois são locais essenciais para debates e discussões sobre as instâncias de poder, suas atuações, e sobre as possíveis formas de se opor à sua força esmagadora. Ao discutir o movimento Occupy Wall Street ${ }^{25}$, o autor lembra as várias praças

25. Movimento de protesto norte-americano contra os abusos do sistema capitalista avançado adotado nos Estados Unidos e em algumas outras realidades mundiais, que traz como consequência grandes desigualdades socioeconômicas. O movimento teve 
ocupadas pelo mundo nas manifestações recentes contra os regimes políticos e econômicos, dizendo que "(...) o poder coletivo dos corpos no espaço público ainda é o instrumento mais eficaz de oposição quando todos os outros meios de acesso encontram-se bloqueados." (HARVEY, 2014, p.281). Reitera-se que essas praças não eram apenas espaços vazios capazes de reunir um grande grupo de manifestantes, mas, em todos os casos, eram espaços de considerável relevância simbólica para aquelas populações.

Percebe-se, assim, que esses diversos tipos de eventos, em especial os de maior alcance, são naturais aos espaços públicos, mas não a qualquer tipo de espaço público. Para que um espaço público tenha essas vocações, não basta apenas que ele seja um vazio qualquer na malha urbana; ele prescinde de dois elementos básicos: espaço suficiente para a congregação de um número significativo de pessoas (permitir a reunião de grupos) e a presença de usos e/ ou monumentos simbólicos (edifícios-sede do poder administrativo, igrejas, monumentos patrióticos, entre outros) que serão o alvo ou o motivo da reunião ${ }^{26}$. Para uma melhor

início em 2011 ao ocupar alguns espaços públicos de Wall Street, em Manhattan, Nova York (EUA), um dos distritos financeiros mais importantes do mundo, onde grandes decisões que impactam o globo são tomadas diariamente.

26. Podemos tomar como exemplo o uso da Praça da Estação (Praça Rui Barbosa) em Belo Horizonte, a Praça da Sé em São Paulo, ou o Largo da Carioca, no Rio de Janeiro. 
condição de sediar esses eventos, entretanto, o espaço disponível deve ser idealmente desobstruído, ou seja, deve oferecer uma área ampla na qual não existam canteiros ajardinados ou mobiliário fixo em seu espaço central. Como esses tipos de elementos causam obstrução na passagem das massas e são frequentemente danificados durante os eventos, os espaços públicos muito equipados com mobiliário e jardins são geralmente evitados para grandes concentrações. A existência de áreas desobstruídas também é particularmente útil para a instalação de estruturas temporárias, como palcos e arquibancadas, utilizadas nessas e em outras ocasiões.

Por todas essas características, observa-se que esses eventos são normalmente sediados com maior frequência em espaços centrais e históricos, como os largos e praças secas, e apenas ocasionalmente em praças ajardinadas ou parques. A utilização mais constante desses espaços para eventos, entretanto, vem gerando algumas críticas, em especial quando se tratam daqueles voltados ao lazer. Tais críticas justificam-se porque alguns desses eventos são

Esses espaços são frequentemente utilizados para eventos de diversas naturezas por serem amplos e por serem símbolos do próprio centro dessas cidades - espaços de significação concreta para todos os cidadãos e nos quais esses adquirem grande visibilidade quando reunidos. Os edifícios relevantes em seus entornos ratificam a importância funcional e/ou simbólica desses espaços públicos. 
organizados a partir de grupos privados e com interesses lucrativos, explorando, para tanto, bens públicos. Esse tipo de utilização, na qual o espaço deixa de ser acessado de forma indiscriminada e passa a ser limitado aos que adquiriram ingressos é chamado, junto a iniciativas semelhantes, de "privatização do espaço público" 27.

Outras críticas são relacionadas às ocasionais ameaças representadas por esses eventos ao patrimônio histórico, composto tanto por esses espaços livres públicos quanto pelas edificações que compõem os seus entornos. Em alguns casos percebe-se que esses espaços possuem elementos realmente frágeis e pouco adaptados para as grandes aglomerações populares contemporâneas. Em outros casos, nota-se que essa ameaça é muitas vezes utilizada como um argumento para evitar que os espaços públicos históricos sejam utilizados para apropriações de massa, fazendo com que muitos largos e praças antigas sejam restritas, mais uma vez, a atividades de contemplação e desfile, ou mesmo limitados às atividades características das classes socioeconômicas de renda mais elevada.

27. Podem ser igualmente consideradas iniciativas de privatização do espaço público quaisquer outras que coloquem a satisfação de interesses privados e individuais acima dos interesses da coletividade urbana. Um exemplo é a prática, adotada em algumas praias brasileiras por parte dos bares e restaurantes, de se colocar mesas e cadeiras na faixa de areia, exigindo consumo mínimo para o uso desse mobiliário. Outro exemplo a ser considerado é a realização de eventos em parques públicos, nos quais a entrada (gratuita no cotidiano) é mediada através da compra de ingressos. 


\section{Considerações finais}

Após discorrer sobre as principais funções atualmente atribuídas aos espaços públicos e sobre seus condicionantes, apresentam-se algumas considerações principais. A primeira delas é que a função mais antiga dos espaços públicos - a de circulação, ainda parece ser uma das mais onipresentes e uma das principais (senão a principal) indutoras de vitalidade. Sem ela não há fluxos e sem fluxos não há condições para que as outras funções, em especial a de lazer passivo, ocorram. Em relação aos estacionamentos, pondera-se que a existência de algumas vagas é interessante, pois pode propiciar maior facilidade de acesso, principalmente, para os usuários com mobilidade reduzida. No entanto, atenta-se para o fato de que a disponibilidade de estacionamento tem a capacidade de facilmente eclipsar as demais funções do espaço, muitas vezes, mais proveitosas para a população como um todo.

Em relação à função de sediar as atividades de lazer passivo, observa-se que há maior chance de ocorrer com sucesso quando o espaço é melhor equipado, provido de mobiliário que possa oferecer condições mínimas de conforto aos usuários. Assim, há uma maior chance de que o espaço acolha um maior número e diversidade de apropriações, que podem ser também mais duradouras e mais qualitativas. Em relação ao lazer ativo, observa-se que, embora 
existam atualmente diversos tipos de mobiliário específicos para a prática de esportes e de recreação, muitas vezes a existência de espaço livre e desobstruído, e de revestimentos seguros, já é mais do que o suficiente para que muitas atividades possam ocorrer. O mesmo pode ser observado em relação aos eventos, que demandam, acima de tudo, espaço desobstruído e, preferencialmente, algum elemento simbólico, fazendo com que o espaço público tenha uma relevância mais complexa para seus usuários.

Assim, concluí-se que, para que diversas funções possam coexistir em um mesmo espaço, é desejável que os responsáveis por sua gestão envolvam a população usuária para, juntos, decidirem sobre as prioridades que se deseja conferir ao espaço público e, se preciso for, realizarem ações para desobstruí-lo (inclusive de carros estacionados), garantindo, portanto, uma flexibilidade espacial capaz de promover a acomodação do maior número de atividades possível. Dessa forma, garantindo a disponibilidade de espaço livre, reforçado pelo emprego de mobiliário móvel, pode-se transformá-lo conforme as demandas apresentadas pelas diferentes funções. Ao facilitar sua adaptação, observa-se que o espaço público pode melhor responder ao estilo de vida urbano contemporâneo - de múltiplos perfis, de certa instabilidade e imprevisibilidade, mutável e diverso. 


\section{Referências}

ABBUD, Benedito. Criando paisagens. São Paulo: SENAC, 2006. 207p.

BORJA, Jordi; MUXÍ, Zaida. El espacio público, ciudad y ciudadanía. Barcelona, 2000. 91 p.

CULLEN, Gordon. Paisagem urbana. Lisboa: Edições 70, 2010. 202 p. DELGADO, Manuel. El espacio público como ideología. Madrid: Catarata, 2011. $109 \mathrm{p}$.

GEHL, Jan. Cities for people. Washington, DC: Island Press, 2010. 269 p.

GEHL, Jan. Life between buildings: using public space. Washington: Island Press, 2011. 207 p.

HARRISON, Ted $O$. The economic value of parks and open space. In: CHILDS, Mark C. Squares: a public place design guide for urbanists. Albuquerque: University of New Mexico Press, 2006. p. 37-40.

HARVEY, David. Cidades rebeldes. São Paulo: Martins Fontes, 2014. 294 p.

LEITE, Rogério P. Contra-usos da cidade: lugares e espaço público na experiência contemporânea. Campinas: Editora Unicamp, 2004.

LOFLAND, Lyn $\mathrm{H}$. The public realm: exploring the city's quintessential social territory. New Jersey: Transaction Publishers, 2009. 305 p.

MAGNOLI, Miranda Martinelli. Espaço livre - objeto de trabalho. Paisagem e Ambiente, São Paulo, n. 21, p. 175-198, 2006. Disponível em <http://www.revistas.usp.br/paam/article/view/40249>. Acesso em: 23 mai. 2017.

MEHTA, Vikas. Evaluating public space. Journal of Urban Design, Routledge, v. 19, n. 1, p. 53-88, 2014.

MONTAL, Pierre; NOISETTE, Patrice. Espace public. In: MERLIN, Pierre; $\mathrm{CHOAY}$, Françoise (Orgs.). Dictionnaire de l'urbanisme et de I'aménagement. Paris: PUF, 2005. p.355-357.

OLDENBURG, Ray. The great good place: cafés, coffee shops, bookstores, bars, hair salons and other hangouts at the heart of a 
community. Boston: Da Capo Press, 1999. 336 p.

ROBBA, Fabio, MACEDO, Silvio S. Praças brasileiras. São Paulo: EDUSP, 2010. $311 \mathrm{p}$.

SITTE, Camillo. L'art de bâtir les villes: I'urbanisme selon ses fondements artistiques. Paris: Éditions du Seuil, 1996. 188 p.

WHYTE, William $\mathrm{H}$. The social life of small urban spaces. Washington, D.C.: Conservation Foundation, 1980. 125 p. 